\begin{tabular}{|c|c|c|}
\hline \multirow{3}{*}{$\begin{array}{r}\text { Case Reports in } \\
\text { Gastroenterology }\end{array}$} & \multirow{2}{*}{\multicolumn{2}{|c|}{ Case Rep Gastroenterol 2015;9:171-178 }} \\
\hline & & \\
\hline & $\begin{array}{l}\text { DOI: 10.1159/000430947 } \\
\text { Publisned ontine: IVIay } 28,2015\end{array}$ & $\begin{array}{l}\text { ( } 2015 \text { S. Karger AG, Basel } \\
1662-0631 / 15 / 0092-0171 \$ 39.50 / 0 \\
\text { www.karger.com/crg }\end{array}$ \\
\hline & \multicolumn{2}{|c|}{$\begin{array}{l}\text { This is an Open Access article licensed under the terms of the Creative Common } \\
\text { Attribution-NonCommercial } 3.0 \text { Unported license (CC BY-NC) (www.karger.com/OA } \\
\text { license), applicable to the online version of the article only. Distribution permitted for non } \\
\text { commercial purposes only. }\end{array}$} \\
\hline
\end{tabular}

\title{
Iatrogenic Colonic Perforation due to Computed Tomographic Colonography
}

\author{
Takashi Kato $^{a}$ Tsukasa Muroya $^{d} \quad$ Takayuki Goda $^{\text {e }}$ Ken Takabayashi ${ }^{\text {b }}$ \\ Kiyotaka Sasaki $^{a}$ Toshiyuki Takahashi ${ }^{c}$ Shoichi Horita ${ }^{a}$ \\ Departments of ${ }^{\mathrm{a}}$ Internal Medicine, ${ }^{\mathrm{b}}$ Radiology and ${ }^{\mathrm{C}}$ Pathology, Hokkaido \\ Gastroenterology Hospital, Sapporo, and Departments of ${ }^{\mathrm{d}}$ Radiology and \\ 'Gastroenterology, Ishikari Hospital, Ishikari, Japan
}

\section{Key Words}

Computed tomographic colonography $\cdot$ Complication $\cdot$ Perforation $\cdot$ Pneumoperitoneum

\begin{abstract}
Although the complications of computed tomographic colonography (CTC) are very rare, CTC is associated with potential risk of colonic perforation. In the present report we describe two cases of colonic perforation secondary to CTC. In the first case with ascending colonic carcinoma, insertion of a rigid double-balloon catheter caused direct rectal wall perforation. In the second case with obstructive colonic carcinoma, pneumoperitoneum developed due to automated carbon dioxide insufflation. Both patients were asymptomatic after examination and recovered without any complications. Based on the findings of the current cases, we recommend that a soft-tip catheter be used for CTC, and suggest that colonic perforation can occur even with automatic insufflation, depending on patient characteristics.
\end{abstract}

(C) 2015 S. Karger AG, Basel

\section{Introduction}

Colorectal cancer (CRC) is one of the most common cancers worldwide. If detected at an early stage, CRC can often be successfully treated. Therefore, CRC screening has become increasingly important. Colonoscopy is currently the main examination method both for the investigation of symptomatic patients and for CRC screening. However, colonoscopy is 
Kato et al.: Iatrogenic Colonic Perforation due to Computed Tomographic Colonography

an invasive examination and has serious complications, such as bleeding, perforation and death [1].

Computed tomographic colonography (CTC) is increasingly used both for CRC screening and for patients with symptoms suggestive of CRC, as an alternative technique to colonoscopy. Compared with colonoscopy, one of the main advantages of CTC has been its superior safety profile. No deaths associated with CTC have been reported in the literature [2-6]. However, CTC also has some complications, such as colonic perforation or vasovagal reactions [2-6]. The most significant complication of CTC is colonic perforation; although its risk is very low, it can be associated with substantial morbidity [2-6]. To minimize complications arising from CTC, it is important to know the details of cases in whom those complications arise. However, only a few such cases have been reported in the literature [7-12]. Here, we describe two cases of colonic perforation secondary to CTC and present a brief review of the literature.

\section{Case Reports}

\section{Case 1: Rectal Perforation due to a Rectal Catheter}

An 83-year-old man with a medical history of lumbar canal stenosis was referred to Ishikari Hospital, Hokkaido, Japan, with anemia (hemoglobin $10.2 \mathrm{mg} / \mathrm{dl}$ ). A computed tomography (CT) scan of the abdomen revealed focal thickening of the ascending colon that suggested colonic tumor. Colonoscopic examination revealed a tumor encircling the ascending colon. CTC was performed the next day to investigate the rest of the colon and for preoperative examination of the colonic tumor. After a catheter tip had been sufficiently lubricated with jelly, a rigid double-balloon catheter, which is used mainly for double-contrast barium enema, was inserted through the anus to the rectum by an experienced nurse with the patient in the left lateral position. Insertion into the rectum was accomplished smoothly, without force, in one procedure. The patient did not complain of any abdominal discomfort. After an intrarectal balloon had been inflated, manual insufflation of carbon dioxide $\left(\mathrm{CO}_{2}\right)$ gas by means of a hand-held bulb was begun by a radiographer experienced in CTC.

Since abnormally high pressure was felt after insufflation of approximately $1 \mathrm{l}$, the procedure was paused and supine CT images were obtained. These images revealed extraluminal air in the perirectal fat and the retroperitoneum (fig. 1a, b). On CTC, rectal perforation was observed in the anterior wall of the upper rectum, which suggested that it had been created by catheter insertion (fig. 1a). Residual fluid in the rectum was discharged through the catheter and the examination was suspended. After the examination, the patient did not complain of abdominal pain, and his vital signs were stable. Physical examination revealed no lower abdominal tenderness on palpation. Therefore, he was treated conservatively with antibiotics, no oral intake and intravenous hyperalimentation.

The next day, the patient developed mild fever $\left(37.6^{\circ} \mathrm{C}\right)$, but remained asymptomatic. on the second day after CTC, he was afebrile. Blood tests on the third day after CTC indicated that he had mild inflammation (C-reactive protein [CRP] levels were $5.18 \mathrm{mg} / \mathrm{dl}$ ); however, CRP had decreased to $2.03 \mathrm{mg} / \mathrm{dl}$ on the fifth day after CTC. Ten days after CTC, colonoscopy was performed to evaluate the perforation site. An approximately 8-mm perforation was still present at the anterior wall of the rectum (fig. 1c). Therefore, two endoscopic clips were used to close the perforation site of the rectum. Twenty days after CTC, a CT scan revealed no free air around the rectum and colonoscopy showed closure of the perforation. Approximately 1 month after CTC, a laparoscopic ileocecal resection was performed to remove the 
Kato et al.: Iatrogenic Colonic Perforation due to Computed Tomographic Colonography

tumor. The postoperative course was uneventful, and the patient was discharged 1 month after surgery.

\section{Case 2: Pneumoperitoneum due to Automated $\mathrm{CO}_{2}$ Insufflation}

An 86-year-old woman with hypertension was referred to Hokkaido Gastroenterology Hospital, Hokkaido, Japan, with an elevated serum carcinoembryonic antigen level (25.5 ng/ $\mathrm{ml}$ ). A CT scan of the abdomen revealed focal thickening of the transverse colon that suggested colonic tumor. Therefore, she was admitted for evaluation of suspected colonic cancer. Colonoscopic examination revealed an obstructive tumor in the transverse colon and no information on the proximal side of the obstruction. The examination was finished after a biopsy specimen had been obtained from the tumor for histological assessment.

On the same day, CTC was performed after colonoscopy to investigate the rest of the colon and for preoperative examination. A 24-French flexible double-balloon catheter was inserted into the rectum with the patient in the left lateral position, and automated colonic insufflation was performed by an experienced radiographer using an ENIMA $\mathrm{CO}_{2}$ device (Horii). Distension pressure was set to $0-20 \mathrm{~mm} \mathrm{Hg}$. During insufflation, the patient was first placed in the right lateral decubitus position for delivery of $1.4 \mathrm{l} \mathrm{of} \mathrm{CO}_{2}$. She was then placed in the supine position until a total of approximately $2 \mathrm{l}$ of $\mathrm{CO}_{2}$ had been delivered. She was then rolled into the left decubitus position. Images were acquired in the supine and left decubitus positions. At the end of the examination, residual gas and fluid in the rectum was discharged through the catheter. The patient did not complain of abdominal pain during the examination.

When reviewing the first stack of axial images obtained in the supine position after examination, a substantial amount of free air in the peritoneal cavity was detected (fig. 2a). The patient's vital signs were stable. Physical examination revealed no abdominal tenderness on palpation. Therefore, she was treated conservatively with antibiotics, no oral intake and intravenous hyperalimentation. The next day, she developed mild fever $\left(37.6^{\circ} \mathrm{C}\right)$, but remained asymptomatic. Blood tests 2 days after CTC showed that she had mild inflammation (white blood cell count and CRP levels were 10,630 $\mu \mathrm{l}$ and $2.73 \mathrm{mg} / \mathrm{dl}$, respectively); however, she remained asymptomatic. Approximately 2 weeks after CTC, a right hemicolectomy was performed to remove the tumor. No perforation site was detected in surgical findings. The postoperative course was uneventful, and the patient was discharged 1 month after the surgery. Based on pathological findings, no perforation site was detected; however, multiple air bubbles were observed in the tumor and the mesentery around the tumor, which indicated that pneumoperitoneum had occurred at the tumor site (fig. $2 b, c$ ).

\section{Discussion}

Although complications of CTC mainly occur during gas insufflation, direct rectal wall perforation due to catheter insertion should not be ignored as one possible cause of CTC complications. Burling et al. [3] reported nine case of colonic perforation due to CTC among 17,067 examinations in the United Kingdom. In one of these cases the cause of the perforation was direct traumatic insertion of the rectal catheter through the rectal wall. Thin flexible catheters should be selected for use in CTC, not the rigid types that are used for doublecontrast barium enema, because the role of the rectal catheter in CTC is only the minimal flow of gas insufflation.

A double-balloon catheter was thought to be necessary for the examination of the first patient reported here because based on the patient's physical condition associated with ad- 
Kato et al.: Iatrogenic Colonic Perforation due to Computed Tomographic Colonography

vanced age, incontinence for gas insufflation was anticipated. Unfortunately, a thin flexible double-balloon catheter for CTC was not available at the time of the examination. An experienced nurse performed the catheter insertion in this case. She did not feel any resistance during the insertion procedure; however, rectal injury due to catheter insertion nonetheless occurred.

This type of injury may be related to the distance of catheter insertion. Anatomically, the puborectalis muscle forms a sharp curve approaching a right angle between the rectum and the anus. The tip of a catheter that is inserted through the anus will collide with the anterior rectal wall perpendicularly after approximately only $5 \mathrm{~cm}$ insertion [13]. Deep insertion of a rigid catheter in an elderly patient with a fragile rectal wall might cause damage to the rectal wall as in our case. ESGAR consensus [14] and ACR practice parameters [15] recommend a soft-tip (non-rigid) catheter for CTC; however, these guidelines are not widely recognized in Japan.

Perforation occurring during gas insufflation is associated with factors including those related to the insufflation technique and to individual patient characteristics [16]. In our second case, CTC was performed by an experienced radiographer, and the amount of automatic $\mathrm{CO}_{2}$ gas insufflation was only 2.0 l. Therefore, we believe that the cause of perforation in this case was not due to the insufflation technique. Patients who have weakening of the colonic wall or colonic obstruction may be at greater risk of perforation due to CTC [16]. Active colitis (inflammatory bowel disease or acute diverticulitis), recent colonic surgery or deep colonic biopsy or polypectomy/mucosal resection prior to CTC are considered to weaken the colonic wall [16]. Any cause of colonic obstruction, for example obstructive CRC or inguinal hernias, and specifically left-sided hernias containing the sigmoid colon, may predispose a patient to perforation due to overdistension $[12,16]$.

In our second case, a combination of factors was likely the cause for pneumoperitoneum, such as the patient's age, obstructive colonic carcinoma and pathological characteristics of the tumor. On the other hand, this patient underwent same-day colonoscopy before CTC, and thus it is not possible to exclude the possibility that pneumoperitoneum might have occurred at colonoscopy. However, in previous studies, perforation diagnosed at CTC was reported as a complication of CTC despite same-day colonoscopy having been performed previously $[5,6]$.

Table 1 summarizes the reported cases of colonic perforation due to CTC, including our two cases described here. To our knowledge, 35 cases with colonic perforation due to CTC have been reported in the literature [2-12,17]. In this summary, the symptomatic perforation rate was $44.9 \%$. Surgical treatment was required in just $37.8 \%$ of the patients, and no deaths were recorded. Our two patients also received conservative treatment and recovered without any complications. It is noteworthy that patients with asymptomatic perforation due to CTC might be treated conservatively rather than surgically. In contrast, reported cases of perforation at colonoscopy more often resulted in surgery, and death has rarely been reported [1].

In conclusion, complications of CTC are very rare, but CTC carries a potential risk of colonic perforation. A soft-tip catheter should be used for CTC and the distance of catheter insertion should be noted. According to a patient's specific condition, it is necessary to recognize that colonic perforation can happen even with automatic insufflation. 
Kato et al.: Iatrogenic Colonic Perforation due to Computed Tomographic Colonography

\section{References}

1 Bowles CJ, Leicester R, Romaya C, Swarbrick E, Williams CB, Epstein 0: A prospective study of colonoscopy practice in the UK today: are we adequately prepared for national colorectal cancer screening tomorrow? Gut 2004;53:277-283.

2 Pickhardt PJ: Incidence of colonic perforation at CT colonography: review of existing data and implications for screening of asymptomatic adults. Radiology 2006;239:313-316.

-3 Burling D, Halligan S, Slater A, Noakes MJ, Taylor SA: Potentially serious adverse events at CT colonography in symptomatic patients: national survey of the United Kingdom. Radiology 2006;239:464-471.

-4 Atalla MA, Rozen WM, Niewiadomski OD, Croxford MA, Cheung W, Ho YH: Risk factors for colonic perforation after screening computed tomographic colonography: a multicentre analysis and review of the literature. J Med Screen 2010;17:99-102.

5 Sosna J, Blachar A, Amitai M, Barmeir E, Peled N, Goldberg SN, Bar-Ziv J: Colonic perforation at CT colonography: assessment of risk in a multicenter large cohort. Radiology 2006;239:457-463.

6 Iafrate F, Iussich G, Correale L, Hassan C, Regge D, Neri E, Baldassari P, Ciolina M, Pichi A, Iannitti M, Diacinti D, Laghi A: Adverse events of computed tomography colonography: an Italian National Survey. Dig Liver Dis 2013;45:645-650.

7 Kamar M, Portnoy 0, Bar-Dayan A, Amitai M, Munz Y, Ayalon A, Zmora O: Actual colonic perforation in virtual colonoscopy: report of a case. Dis Colon Rectum 2004;47:1242-1246.

$>8$ Coady-Fariborzian L, Angel LP, Procaccino JA: Perforated colon secondary to virtual colonoscopy: report of a case. Dis Colon Rectum 2004;47:1247-1249.

-9 Young BM, Fletcher JG, Earnest F, Fidler JL, MacCarty RL, Johnson CD, Huprich JE, Hough D: Colonic perforation at CT colonography in a patient without known colonic disease. AJR Am J Roentgenol 2006;186: 119-121.

10 Wong SH, Wong VW, Sung JJ: Virtual colonoscopy-induced perforation in a patient with Crohn's disease. World J Gastroenterol 2007;13:978-979.

11 Bassett JT, Liotta RA, Barlow D, Lee D, Jensen D: Colonic perforation during screening CT colonography using automated $\mathrm{CO}_{2}$ insufflation in an asymptomatic adult. Abdom Imaging 2008;33:598-600.

$\checkmark 12$ Belo-Oliveira P, Curvo-Semedo L, Rodrigues H, Belo-Soares P, Caseiro-Alves F: Sigmoid colon perforation at CT colonography secondary to a possible obstructive mechanism: report of a case. Dis Colon Rectum 2007;50:1478-1480.

13 Haruta K, Yamahata A, Shinoda K, Ito M, Kasugai K, Suzumura H: Safe length for enema catheter insertion: estimation based on lower gastrointestinal series imaging findings in adults (in Japanese). Kango Kenkyu 2011;34:71-75.

14 Neri E, Halligan S, Hellström M, Lefere P, Mang T, Regge D, Stoker J, Taylor S, Laghi A; ESGAR CT Colonography Working Group: The second ESGAR consensus statement on CT colonography. Eur Radiol 2013;23:720-729.

15 American College of Radiology: ACR-SAR-SCBT-MR practice parameters for the performance of computed tomography (CT) colonography in adults. Chicago, IL, American College of Radiology, 2005-2009, revised 2014. http://www.acr.org/ /media/ACR/Documents/PGTS/guidelines/CT_Colonography.pdf.

16 Pendsé DA, Taylor SA: Complications of CT colonography: a review. Eur J Radiol 2013;82:1159-1165.

17 Atkin W, Dadswell E, Wooldrage K, Kralj-Hans I, von Wagner C, Edwards R, Yao G, Kay C, Burling D, Faiz O, Teare J, Lilford RJ, Morton D, Wardle J, Halligan S; SIGGAR Investigators: Computed tomographic colonography versus colonoscopy for investigation of patients with symptoms suggestive of colorectal cancer (SIGGAR): a multicentre randomised trial. Lancet 2013;381:1194-1202. 
Kato et al.: Iatrogenic Colonic Perforation due to Computed Tomographic Colonography

Table 1. Summary of reported cases of colonic perforation due to CTC, including the two current cases

\begin{tabular}{|c|c|}
\hline Age, years $(n=26)$ & $47-87$ \\
\hline Average & 75 \\
\hline \multicolumn{2}{|l|}{$\operatorname{Sex}(n=24)$} \\
\hline Male & 15 \\
\hline Female & 9 \\
\hline \multicolumn{2}{|l|}{ Concomitant disease $(n=36)$} \\
\hline Yesa $^{a}$ & $25(69.4 \%)$ \\
\hline Diverticulosis & 9 \\
\hline Colonic carcinoma & 5 \\
\hline Inguinal hernia & 5 \\
\hline Inflammatory bowel disease & 4 \\
\hline Post colorectal surgery & 2 \\
\hline No & $11(31.6 \%)^{b}$ \\
\hline \multicolumn{2}{|l|}{ Gas $(\mathrm{n}=33)$} \\
\hline Room air & $26(78.8 \%)$ \\
\hline $\mathrm{CO}_{2}$ & $7(21.2 \%)$ \\
\hline \multicolumn{2}{|l|}{ Insufflation method $(n=33)$} \\
\hline Manual & $28(84.9 \%)^{c}$ \\
\hline Automated & $5(15.2 \%)$ \\
\hline \multicolumn{2}{|l|}{ Associated symptoms $(n=29)$} \\
\hline Symptomatic & $13(44.8 \%)$ \\
\hline Abdominal pain & 6 \\
\hline Abdominal discomfort & 4 \\
\hline Abdominal pain with peritonitis & 2 \\
\hline Unrecorded & 1 \\
\hline Asymptomatic & $16(55.1 \%)$ \\
\hline \multicolumn{2}{|l|}{ Treatment $(n=37)$} \\
\hline Surgery & $14(37.8 \%)$ \\
\hline Conservative & $23(62.2 \%)$ \\
\hline \multicolumn{2}{|l|}{ Clinical outcome $(n=37)$} \\
\hline Recovered & $37(100 \%)$ \\
\hline Died & $0(0 \%)$ \\
\hline \multicolumn{2}{|c|}{$\begin{array}{l}\text { a Including overlapped data. } \\
\text { b Including one case which had undergone a recent colonic biopsy [4]. } \\
\text { c Including one case which involving switching from automatic to } \\
\text { manual insufflation [7]. }\end{array}$} \\
\hline
\end{tabular}




\begin{tabular}{|c|c|c|}
\hline \multirow{3}{*}{$\begin{array}{l}\text { Case Reports in } \\
\text { Gastroenterology }\end{array}$} & \multirow{2}{*}{\multicolumn{2}{|c|}{ Case Rep Gastroenterol 2015;9:171-178 }} \\
\hline & & \\
\hline & DOI: $10.1159 / 000430947$ & $\begin{array}{l}\text { ( } 2015 \text { S. Karger AG, Basel } \\
\text { www.karger.com/crg }\end{array}$ \\
\hline
\end{tabular}

Kato et al:. Iatrogenic Colonic Perforation due to Computed Tomographic Colonography
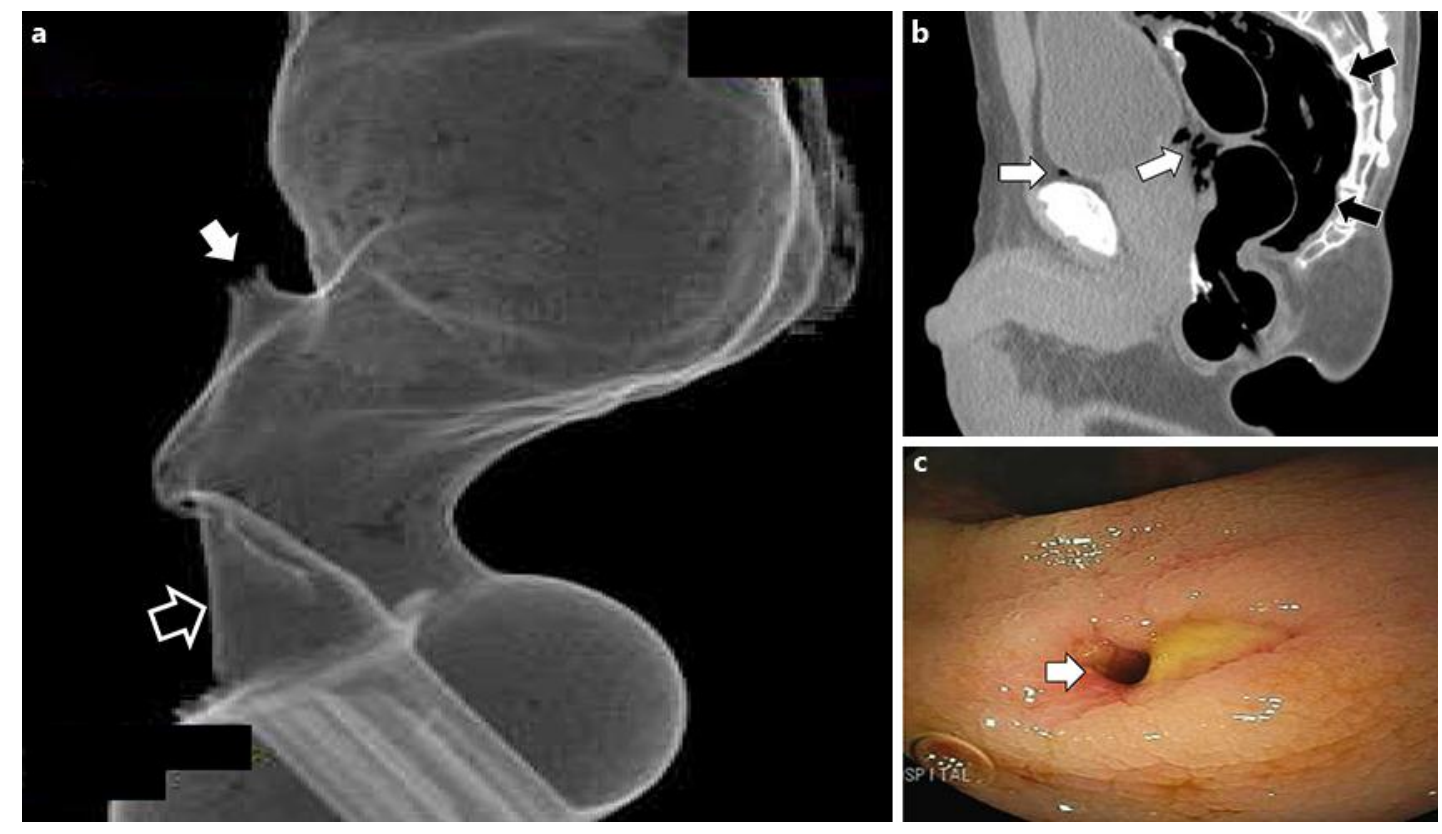

Fig. 1. a CT air-contrast enema image showing the obvious perforation site (white arrow) in the anterior wall of the upper rectum and the rectal catheter tip (black arrow). b Sagittal CT image showing extraluminal bubbles (white arrows) in the pelvis and a large quantity of free air (black arrows) posterior to the rectum. c Colonoscopy showing an approximately 8-mm hole (white arrow) in the anterior wall of the rectum. 


\begin{tabular}{|c|c|c|}
\hline \multirow{3}{*}{$\begin{array}{r}\text { Case Reports in } \\
\text { Gastroenterology }\end{array}$} & \multirow{2}{*}{\multicolumn{2}{|c|}{ Case Rep Gastroenterol 2015;9:171-178 }} \\
\hline & & \\
\hline & DOI: 10.1159/000430947 & $\begin{array}{l}\text { (c) } 2015 \text { S. Karger AG, Basel } \\
\text { www.karger.com/crg }\end{array}$ \\
\hline
\end{tabular}

Kato et al.: Iatrogenic Colonic Perforation due to Computed Tomographic Colonography

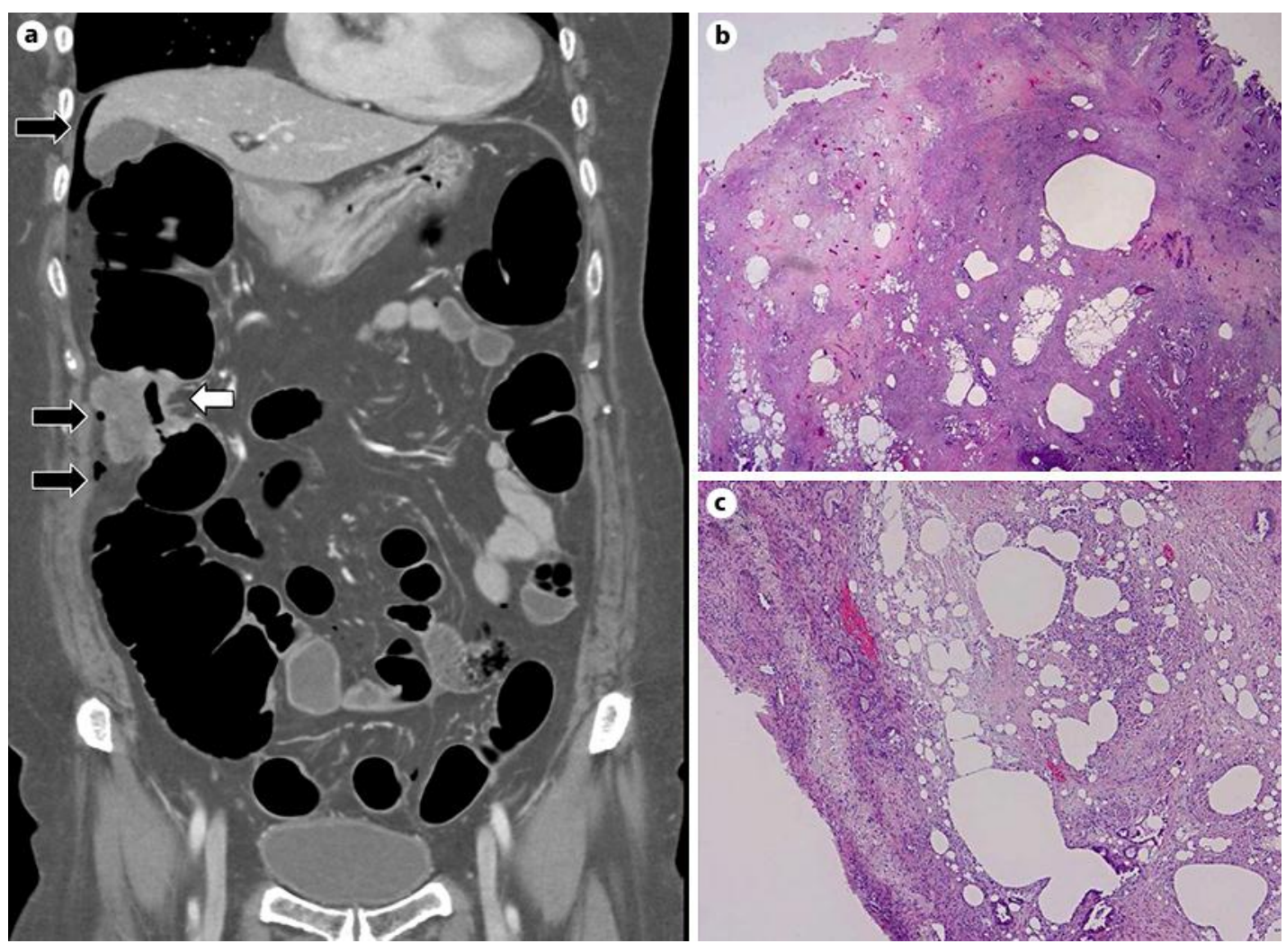

Fig. 2. a Coronal CT image showing a colonic tumor in the transverse colon (white arrow); extraluminal gas was observed not only around the tumor but around the liver as well (black arrows). b, c In pathological findings, multiple air bubbles were observed in the colonic carcinoma (b) and the mesentery around the tumor (c). 